\title{
Trachyonychia successfully treated with low-dose acitretin in a paediatric patient
}

\author{
Aleksandra Siekierko, Magdalena Sadowska, Michał Niedźwiedź, Karolina Kijowska, Magdalena Żak, \\ Małgorzata Skibińska, Aleksandra Lesiak, Joanna Narbutt
}

Department of Dermatology, Paediatric Dermatology and Oncology, Biegański's Hospital, Lodz, Poland

Adv Dermatol Allergol 2022; XXXIX (5): 990-991 DOI: https://doi.org/10.5114/ada.2022.113195

Trachyonychia is a rare disorder of the nail unit in which surface of the nails is rough like sandpaper or glossy with pits. It is mostly idiopathic but can also be associated with other diseases. Diagnosis is based mainly on the clinical picture as histopathology is not routinely evaluated. Treatment of the condition is challenging and usually disappointing [1, 2]. We report a case of trachyonychia successfully treated with acitretin in a paediatric patient.

We present an 8-year-old girl with 6 months' duration of changes in all twenty nails and no comorbidities. Examination revealed rough surface, excessive longitudinal ridging and onychoschizia in all twenty nails. Nail surfaces were opaque with hyperkeratotic cuticles (Figure 1). The skin, hair, mucous membranes and dental examination at the time did not show any abnormalities. There was no personal or family history of skin diseases including psoriasis and lichen planus. The nail biopsy was not performed due to the high risk of possible iatrogenic damage to the nail matrix. Mycological tests were negative. The diagnosis of idiopathic trachyonychia was based on the patient's history and clinical picture.

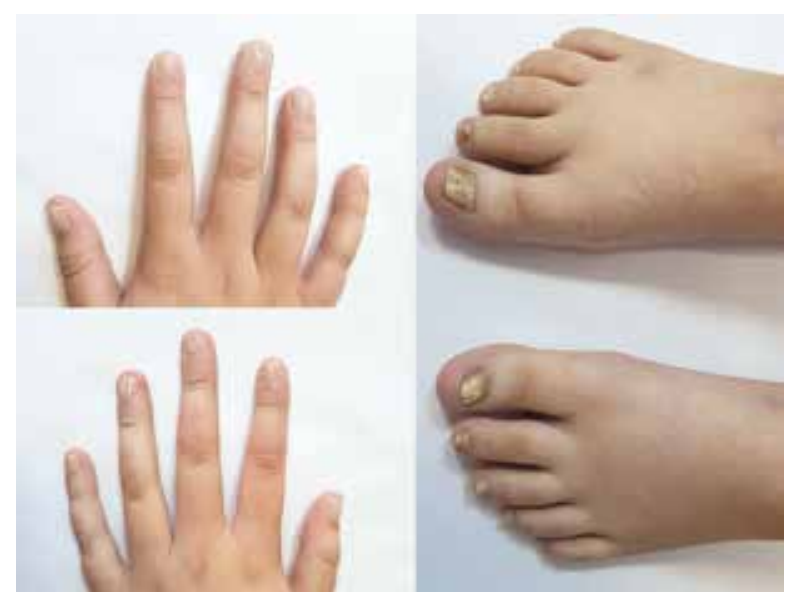

Figure 1. Nails before treatment
Initially, oral acitretin $10 \mathrm{mg} /$ day $(0.3 \mathrm{mg} / \mathrm{kg} /$ day $)$ was administered combined with short-term treatment of topical $0.05 \%$ clobetasol propionate ointment. After 3 months of oral therapy, a significant, assessed as $70 \%$, improvement in all nails was observed. Treatment was continued with excellent results for further 5 months, when the dose was reduced to $10 \mathrm{mg} \mathrm{ev}$ ery other day for the following 3 months (Figure 2). No significant side effects were observed during the treatment. Interestingly, during the follow-up visit at the end

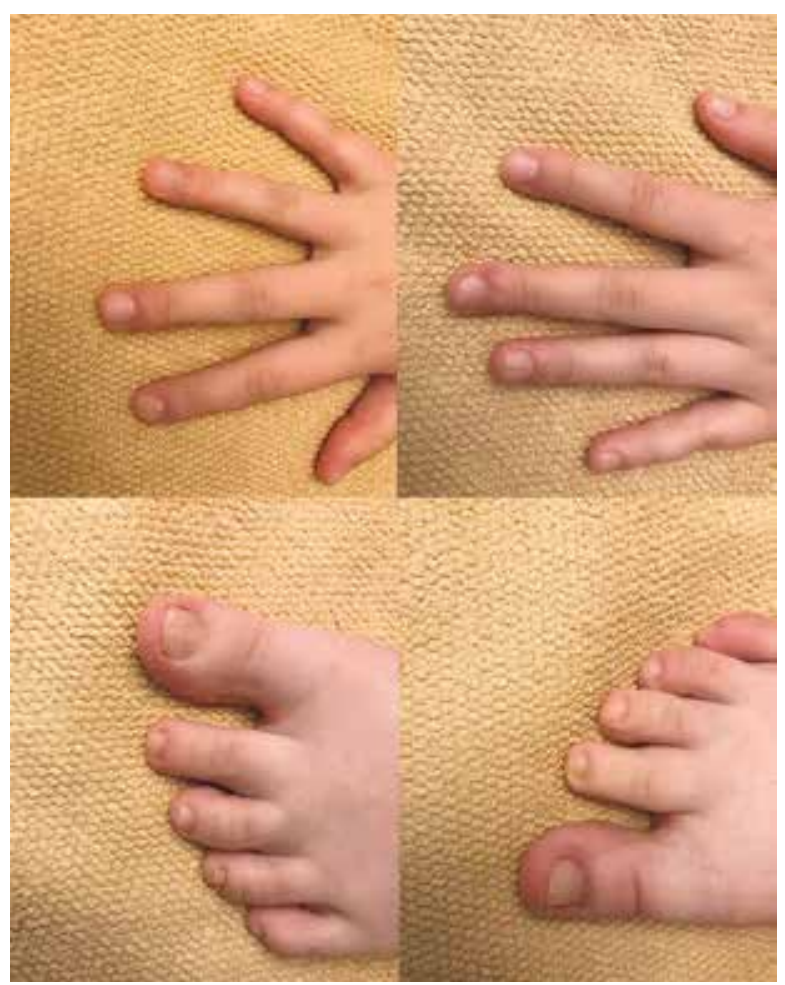

Figure 2. Nails after treatment

Address for correspondence: Aleksandra Siekierko MD, Department of Dermatology, Paediatric Dermatology and Oncology, Biegański's Hospital, Lodz, Poland, e-mail: agrela.ag@gmail.com

Received: 2.11.2021, accepted: 8.11.2021 
of the therapy, the clinical examination revealed hair casts in her scalp hair.

Trachyonychia is also known as twenty-nail dystrophy, however any number of nails can be affected. The peak onset is between 3 and 12 years of age but can also occur in adults [1]. There are two types of trachyonychia: opaque and shiny, which can coexist. Opaque trachyonychia is more severe and common. It is characterized by thin, fragile, and rough nails with longitudinal ridging and hyperkeratotic cuticles. In shiny trachyonychia nails are opalescent with multiple pits.

Trachyonychia can be idiopathic or can be associated with non-dermatological or dermatological conditions, such as alopecia areata, lichen planus and psoriasis [1]. There is no available evidence-based treatment for the condition. Treatment modalities include topical or intralesional corticosteroids and oral medications, such as cyclosporine, retinoids, corticosteroids, biotin, and tofacitinib [1, 2]. Case reports, showing excellent results of systemic acitretin treatment in patients with trachyonychia, are available in the literature. Tosti et al. [3] described a significant improvement after treatment with $0.3 \mathrm{mg} / \mathrm{kg} /$ day of acitretin for 7 months in a 38-year-old man with trachyonychia and concomitant psoriasis. In another case report, Kolbach-Rengifo et al. [4] presented a 45 -year-old woman treated with $25 \mathrm{mg} /$ day $(0.4 \mathrm{mg} / \mathrm{kg} /$ day) of acitretin for 2 months with subsequent lowering the dose to every other day. Treatment was continued for 10 months with very good results. In both cases there was no evidence of recurrence of the lesions. In our case, nail changes resolved within 8 months of treatment with $0.3 \mathrm{mg} / \mathrm{kg} /$ day of oral acitretin. To avoid relapse, acitretin $0.3 \mathrm{mg} / \mathrm{kg} /$ day was continued every other day for the next 3 months. During one of her last follow-up visit we noticed hair casts on her scalp hair. They are defined as white concretions which freely move along the hair [5]. They can be divided into parakeratotic usually seen in psoriasis, seborrheic dermatitis and traction or peripilar which can be seen in young women [6]. The exact pathogenesis is unknown, but it is important to distinguish them from nits in pediculosis capitis [5-7]. In the available literature there have not been any patients reported with both trachyonychia and pseudonits and most likely it was an unrelated finding.

To the best of our knowledge, this is the first case describing the use of acitretin in the treatment of trachyonychia in children. In conclusion, we think that treatment with acitretin should be considered in severe cases of trachyonychia in children.

\section{Acknowledgments}

This research was funded by statutory activities/ funds of the Medical University of Lodz no. 503/5-06404/503-01.

\section{Conflict of interest}

The authors declare no conflict of interest.

\section{References}

1. Haber JS, Chairatchaneeboon M, Rubin Al. Trachyonychia: review and update on clinical aspects, histology, and therapy. Skin Appendage Disord 2017; 2: 109-15.

2. Jacobsen AA, Tosti A. Trachyonychia and twenty-nail dystrophy: a comprehensive review and discussion of diagnostic accuracy. Skin Appendage Disord 2016; 2: 7-13.

3. Tosti A, Bellavista S, Iorizzo M, Vincenzi C. Occupational trachyonychia due to psoriasis: report of a case successfully treated with oral acitretin. Contact Dermatitis 2006; 54: $123-4$.

4. Kolbach-Rengifo M, Navajas-Galimany L, Araneda-Castiglioni D, Reyes-Vivanco C. Efficacy of acitretin and topical clobetasol in trachyonychia involving all twenty nails. Indian J Dermatol Venereol Leprol 2016; 82: 732-4.

5. Campos-Muńoz L, Fueyo-Casado A, Carranza-Romero C, et al. Peripilar hair casts. J Am Acad Dermatol 2017; 76 (2S1): S3-4.

6. Lukoviek V, Malvehy J, Puig S, Podlipnik S. Pseudonits or hair casts. Dermatol Pract Concept 2020; 10: e2020072.

7. Parmar SS, Parmar KS, Shah BJ. Hair casts. Indian Dermatol Online J 2014; 5: 554-5. 